This document is published in:

Energy Economics, (2007), 29 (2), 259-276.

DOI: http://dx.doi.org/10.1016/j.eneco.2006.04.007

(C) 2006 Elsevier B.V. 


\title{
Supply security and short-run capacity markets for electricity
}

\author{
Anna Creti ${ }^{a, *}$, Natalia Fabra ${ }^{\text {b,c }}$ \\ a IEFE, Università Luigi Bocconi, Italy \\ ${ }^{\mathrm{b}}$ Universidad Carlos III, Spain \\ c CEPR, United Kingdom
}

\begin{abstract}
The creation of electricity markets has raised the fundamental question as to whether markets create the right incentives for the provision of the reserves needed to maintain supply security in the short-run, or whether some form of regulation is required. In some states in the US, electricity distributors have been made responsible for providing such reserves by contracting capacity in excess of their forecasted peak demand. The so-called Installed Capacity Markets provide one means of contracting reserves, and are the subject of this paper. Under monopoly as well as under perfect competition, we identify firms' short-run opportunity costs of committing resources in the capacity market and the costs of inducing full capacity commitment. The long-run investment problem is not considered. From a welfare viewpoint, we also compare the desirability of providing reserves either through capacity markets or through the demand side (i.e. power curtailments). At the optimum, capacity obligations equal peak demand (plus expected outages) and the capacity deficiency rate (which serves as a price cap) is set at firms' opportunity costs of providing full capacity commitment.
\end{abstract}

Keywords: Security of supply; Capacity markets; Regulation

\section{Introduction}

Unlike virtually any other commodity, electricity is extremely costly-if not impossible-to store. Furthermore, electricity markets differ from virtually all other markets in that they require instantaneous and continuous balancing of its demand and supply resources. A failure to equate demand and supply endangers the stability of the network and may result in disruptions that not only

\footnotetext{
* Corresponding author. Viale Filippetti 9, 20122 Milan, Italy. Tel.: +39 025836 3812; fax: +39 0258363890 E-mail address: anna.creti@unibocconi.it (A. Creti).
} 
affect the market participants that caused the imbalance, but the system as a whole. The challenge imposed by the need to maintain continuous electrical equilibrium is further exacerbated by the fact that almost all end-consumers do not have the metering technology to observe nor the economic incentives to respond to real-time prices. This implies that little or none of the supply/demand balancing can be done through the demand side. ${ }^{1}$ Thus, the reliability problem in electricity markets has two dimensions: in the short-term, supply security requires the readiness of existing capacity to meet the actual load ${ }^{2}$ supply adequacy, instead, refers to the "long-run performance attributes of the system in attracting investment in generation, transmission, distribution, metering, and control capacity so as to minimize the costs of power supplies" (Joskow, 2005).

Under traditional regulatory schemes, monopolistic electric utilities were responsible for ensuring the security of supply through efficient use of their capacity resources. With the introduction of competition in generation, these regulatory schemes are replaced by market-based mechanisms. Recent experience and the poor performance of some of these restructured electricity markets have led several regulatory authorities to rely on alternative designs, such as capacity obligations, capacity payments or other instruments, aimed at bringing forth the incentives to ensure security of supply (see Forsberg and Fritz, 2001; Hobbs et al., 2001; Klein, 2001 for a detailed analysis of the different mechanisms that have been implemented in practice).

In broad terms, capacity payment systems can be classified as either price-, or quantity-based. In price-based systems, the regulator sets the price for capacity and generators decide how much to make available at that price, whereas in quantity-based systems, the regulator chooses a certain amount of reserves and, through some form of market mechanisms, generators set the price at which they are willing to provide them.

Typically, in price-based systems, capacity availability has been rewarded either through lumpsum payments (as in Argentina and Spain) or via an uplift to energy payments that depends on the probability of outages (as in the former UK pool). These solutions have been frequently criticized, because they create poor incentives to alleviate the capacity problem, and may even worsen it. For instance, generators may try to increase capacity payments by making fewer capacity resources available, thereby increasing, rather than decreasing, the probability of shortage. ${ }^{3}$

Quantity-based systems are the focus of the policy debate in the US. ${ }^{4}$ To date, two quantitybased methods have been adopted: operating reserve markets, and installed or available capacity markets. The main purpose underlying the introduction of the latter has been to ensure that adequate capacity is committed on a daily or seasonal basis to meet system load and reserve requirements. The basic mechanism works as follows: Load Serving Entities (LSEs), e.g. distributors that sell electricity to end-user consumers, must satisfy their capacity obligations, which equal their expected peak monthly loads plus a reserve margin. They can accomplish this, either by internal or bilateral transactions, or through the capacity markets in which generators sell

\footnotetext{
${ }^{1}$ See Borenstein and Holland (2003) and Joskow and Tirole (in press) for an analysis of Real Time Pricing and the potential effects it could have on the performance of electricity markets.

2 The blackout that took place in the US East coast in August 2003 shows that the value of the losses caused by a system imbalance may be substantially large (see Joskow, 2003; The Economist, 2003).

3 See Newbery (1995), and Wolak and Patrick (1997).

${ }^{4}$ Quantity-based systems have also been debated in Europe. Some authors (Oren, 2003; Vázquez et al., 2003) have recently proposed to introduce capacity payments which essentially work as mandatory call options: in exchange of an option premium, generators commit to produce a certain amount of output at a given price as long as the energy price exceeds that threshold. The rationale underlying this proposal is that risk averse generators will face stronger incentives to invest if they are assured to receive a fixed payment, i.e. the option premium, rather than having to solely rely on random energy prices to recover the fixed costs of the investment.
} 
a recall right that empowers the System Operator to recall them in the event of a supply deficit in the energy market, in order to avoid power curtailment. All the generators declaring their available capacity are paid the capacity market equilibrium price, which should be reflective of the overall capacity in the system in relation to the LSEs' obligations. For instance, if an LSE is short of capacity and does not submit a buy bid in the capacity market, a mandatory bid covering its obligation will be submitted by the System Operator. The level of the mandatory bid is chosen by the regulator. As FERC (2001) points out, such a mandatory bid effectively works as a capacity price cap, since "customers will not pay more for capacity than the penalty charge". 5 Capacity markets of this kind have been introduced in several systems, such as New England, New York or Pennsylvania-New Jersey-Maryland (PJM). ${ }^{6}$

The design of the Installed Capacity Markets in PJM, as it was enforced until 2004, has inspired our analysis. The PJM was initially established in 1927 as a centrally dispatched control area pooling the generation and transmission facilities of several utilities. Today, PJM is the largest centrally dispatched electric power system in North America. Since April 1, 1997, when a voluntary bid-based energy market was initiated, the PJM has relied upon capacity obligations to fulfill two objectives: in the short-run, these obligations ensure that generating capacity serves load in high-demand days; in the long-run, the revenues from the sales of capacity "[...] provide a price signal to potential builders of new capacity. An alternate method of addressing long-term reliability is to rely solely on price spikes in the energy market to provide incentives to supply on high-demand days, to provide price signal to reduce consumption, and to provide signal to potential entrants" (Bowring and Gramlich, 2000). After the liberalization of the energy sector, capacity obligations are met through market mechanisms. On October 1, 1998, PJM initiated monthly and multi-monthly capacity markets; daily capacity markets were introduced in 1999 (bilateral transactions on capacity are also allowed). Collectively, these arrangements are known as the Installed Capacity (ICAP) market. The supply in the capacity market is provided by generators in the PJM control area that meet specific technical and security criteria. An interesting feature is that capacity resources can be de-listed, or exported, from the PJM control area and vice versa, imported from neighboring systems. In fact generators sell a recall right to the energy produced by their units and sold to entities outside PJM. This right enables PJM to recall energy exports from capacity resources when needed. When capacity resources are recalled, the supplier is paid the prevailing PJM energy market price. The demand in the capacity market is fixed, as indirectly determined by the System Operator through the choice of LSEs' capacity obligations, following complex rules set forth in the RAA. The current rules require LSEs to own or purchase capacity resources greater than or equal to their expected peak-load plus a reserve margin, which is set on the basis of an annual reliability analysis performed by PJM and the standards established by the North American and the Mid-Atlantic Electric Reliability Councils. An LSE can satisfy its obligation by reliance on self-supply, acquisition in bilateral markets, or acquisition of capacity credits from the daily, monthly and multi-monthly Capacity Credit Markets. If an LSE is short of capacity and does not submit a buy bid in the capacity market, a mandatory bid covering its obligation will be submitted. Such a mandatory bid will

\footnotetext{
${ }^{5}$ Capacity markets in the eastern US are now evolving towards a more flexible model in which a demand curve rather than a fixed capacity requirement determines the capacity market equilibrium. See the analysis by Cramton and Stoft (2005).

6 The Californian Independent System Operator has also considered the possibility of creating a capacity market (CAISO, 2002a,b).
} 
be set equal to the Capacity Deficiency Rate (CDR), which was currently equal to $\$ 170.96$ per MW-day at the end of 2003 (PJM, 2004). ${ }^{7}$

Since the introduction of monthly and multi-monthly capacity credit markets in June 2001, the volume of trades has increased steadily. ${ }^{8}$ Prices in the daily capacity market have been quite low, averaging generally less than $\$ 1$ per MW-day, whereas prices in the monthly and multi-monthly capacity markets have been much higher. ${ }^{9}$ The PJM Market Monitoring Unit (henceforth, MMU) reports that the functioning of the capacity markets has been competitive in 1999 and 2002 (see PJM, 2000, 2003), but 2000 and 2001 have witnessed several attempts to exercise market power. In this respect, the MMU has asserted that "market power remains a serious concern given the extreme inelasticity of demand and high levels of concentration in capacity credit markets. Market power is structurally endemic to PJM capacity markets and any redesign of capacity markets must address market power" (PJM, 2003).

This paper deals with short-term issues, i.e. problems related to supply security and leaves the question of supply adequacy or whether capacity markets offer adequate incentives for "ensuring optimal capacity investment" for future research (von der Fehr et al., 2005). In the light of the ongoing debate about the desirability of introducing capacity markets as a means to achieve supply security, we have developed a stylized model aimed at capturing some of the main features of these markets. Our analysis has two main objectives. The first one is to identify the link between the capacity and energy markets when generators also have the option (subject to a transmission constraint) to sell electricity in an adjacent, more profitable market. With this purpose, we characterize the generators' short-run optimal strategies-which involve the threefold decision of how many resources to commit in the capacity market, and how much energy to offer in the national and foreign energy markets-and investigate how these decisions are affected by the market structure. Our second objective is to analyze the design of capacity markets and determine, within our stylized set-up, the value of the optimal capacity obligation and capacity deficiency rate that should be imposed in these markets. Related to this, we also assess whether it would be preferable to resort to power curtailment as a source of reserves, or to increase the energy price cap in order to avoid the migration of capacity resources to more profitable markets.

The paper is organized as follows. Section 2 describes the model, whereas Sections 3 and 4 characterize the firms' problem under the extreme cases of monopoly and perfect competition. Section 5 provides the solution to the regulator's problem. Section 6 concludes by pointing out the relevance of the paper's results to several aspects of the ICAP markets in the PJM system. We have relegated most proofs to the appendix.

\section{The model}

Consider an electricity industry where total generation capacity is given by $K$. Marginal costs of production are normalized to zero for production levels below capacity, whereas production above capacity is impossible.

\footnotetext{
7 The Capacity Deficiency Rate is designed to reflect the annual fixed cost of a combustion turbine in PJM and the associated transmission investment, including a return on investment, depreciation and fixed operation and maintenance expenses. It is also adjusted for the forced outage rate and thus may change annually.

${ }^{8}$ Monthly and multi-monthly capacity market volume increased from $3.0 \%$ of the load obligation in 2001 to $5.2 \%$ of average obligation in 2003.

${ }^{9}$ Looking at the most recent data available (PJM, 2003; 2004, a), in the PJM-East Region, the volume-weighted average daily price were $\$ 0.59$ for 2002 , and $\$ 0.68$ per MW-day for 2003; the volume-weighted average longer term prices were $\$ 38.21$ for 2002, and \$21.57 per MW-day for 2003 .
} 
There are two energy markets: the national and the foreign market. Suppliers can either sell or buy energy in either of them. For simplicity, the foreign energy market is assumed to be perfectly competitive, and the prevailing foreign price is denoted by $f$. In the national energy market, suppliers compete to sell their production. Demand $D$ is determined in each period as a random variable independent of the market price, i.e. it is perfectly price inelastic. In particular, $D \in[0,1]$ is distributed according to some known distribution function $G(D)$. Prices in the national energy market are capped at $P$. The gross utility of every unit consumed is denoted by $v \geq P$. Alternatively, we will also interpret $v$ as consumers' reservation value, e.g. their costs of resorting to alternative energy sources, or equivalently, the minimum price that consumers will accept to be curtailed.

Exports and imports between the national and foreign energy markets are limited by the amount of total transmission capacity, $\beta$, which is assumed to be symmetrically divided among suppliers through non-tradable transmission rights. ${ }^{10}$ Transmission losses are equal to zero, so that transmission entails no costs.

Furthermore, there exists a capacity market where national suppliers have the option to make their capacity resources available if needed to cover the peaks of demand. When a supplier commits some of his capacity resources, he entitles the regulator to 'recall' them when demand exceeds the capacity that has been offered in the energy market. ${ }^{11}$ The supplier is not obliged to use those committed resources to satisfy the national energy demand otherwise. The demand side in the capacity market is composed of the load serving entities, which are obliged to contract enough capacity resources so as to cover a fraction of their expected demand plus a regulated reserve margin. Hence, total demand in the capacity market-fixed and perfectly inelastic-is indirectly determined by the capacity obligation chosen by the regulator. For simplicity, we will just refer to it as total demand in the capacity market, and will denote it by $\Theta$. The inelasticity of demand for capacity implies that prices need to be capped at some level, $C$. In PJM, for instance, a deficiency charge is assigned to load serving entities who are short of capacity; this deficiency charge acts as a de facto cap on the willingness to pay for capacity.

Throughout the paper, we will make the following assumptions:

A1. The portion of total capacity that cannot be exported (referred to as 'non-exportable capacity') is positive but not enough to satisfy peak demand in the national energy market, i.e. $0<K-\beta<1$.

A2. If the transmission line were fully utilized to import energy from the foreign energy market, this would be enough to satisfy peak demand in the national energy market, i.e. $K+\beta>1$.

A3. The foreign energy price is higher than the national energy price cap, i.e. $f \geq P$.

A4. The unit gross utility $v$ is larger than the foreign price, i.e. $v>f$.

A5. Demand in the capacity market does not exceed peak demand, i.e. $\Theta \leq 1$.

The first two assumptions set upper and lower bounds for aggregate productive capacity $K \in(\beta-1, \beta+1)$, in relation to transmission capacity $\beta$. First, if the transmission line were fully utilized to export energy abroad, the remaining productive capacity (referred to as non-exportable

10 The analysis with tradable transmission rights is available from the authors upon request.

11 If recalled, the generator also has the option to default on its commitment and pay a fine. This penalty is now very high, but it used to be low enough so that generators might find it worthwhile to sell their energy elsewhere and pay the penalty. In this paper, we assume that such a fine is large enough so that it does not pay the generator to default. It is important not to confuse this fine with the deficiency penalty that an LSE has to pay when he is short of capacity — which we denote as $C$ (see discussion in the text). 
capacity) would not be enough to satisfy the peak of demand. Otherwise, there would be no need to have a capacity market. ${ }^{12}$ And second, if the transmission line were fully used to import energy from abroad, there would be enough capacity to satisfy the peak of demand. Otherwise, the regulator could not be sure that all demand would be satisfied even if he offered to pay a very large capacity price for the committed resources.

The third assumption states that the foreign energy price is higher than the national energy price cap. Although we take $f$ to be deterministic, our results would remain unchanged if we assumed that $f$ is the expected value of the foreign energy prices. This is the relevant case for our current purposes, given that if the national market was more profitable in expected terms, there would be no risk of capacity resources migrating to foreign regions, and thus no need (given our previous assumptions) to introduce a capacity market. ${ }^{13}$ Also, as stated by the fourth assumption, the gross utility of every unit consumed, $v$, exceeds the foreign price $f$, as otherwise there would be no energy consumption.

Last, we have assumed that demand in the capacity market does not exceed peak demand, given that there is no need (and it is costly) to demand capacity resources that will never be recalled. This assumption makes sense given the assumption that productive capacity does not suffer any random outages. If capacity was random, as it is in the real world, it could make sense that demand in the capacity market exceeded peak demand in order to absorb such random outages, but not otherwise.

The timing of the game is as follows. Prior to the realization of demand in the energy market, suppliers compete in the capacity market and receive their payments for the amounts committed. Once demand in the energy market is realized and observed by all suppliers, suppliers compete in the national and foreign energy markets. If there is excess demand in the energy market, the regulator recalls the suppliers' committed capacity resources, which are paid at the prevailing national energy market price. Last, suppliers receive their payments for the energy sold.

We now proceed to characterize the Subgame Perfect Equilibrium of the game by backward induction. First, we solve for the energy market competition game. Second, we move to the capacity market competition game to characterize firms' capacity commitments and the equilibrium price, for given $\Theta$ and $C$. Last, we analyze the regulator's problem, who has to choose how many resources to demand in the capacity market, $\Theta$, and has to set the capacity price cap, $C$. Given these optimal choices, he has to decide whether to introduce a capacity market or to resort to power curtailment as a source of reserves.

\section{Monopoly}

Consider first the monopoly case. Since the monopolist faces no competition, he is able to extract all the rents by bidding at the price cap in both the energy and capacity markets. He has nevertheless to decide how much energy to offer, and how many capacity resources to commit. Given that the foreign energy market is more profitable, i.e. $f>P$, the first decision is trivial: the monopolist will fully utilize the transmission link, and he will therefore only offer to produce his non-exportable capacity, $K-\beta$. Note that this decision is independent of what he opts to do in the capacity market.

\footnotetext{
12 See for instance FERC (2001, p.3), "The Commission should impose a reserve capacity requirement on electricity customers only if, without the requirement, the market would fail to elicit either sufficient reserve capacity, or an appropriate mix of sufficient reserve capacity and voluntary curtailment, to meet demand and avoid involuntary curtailments".

13 For instance, this assumption applies to PJM, as its neighboring systems are not subject to price caps.
} 
In the capacity market, the monopolist faces a trade-off when deciding how many capacity resources to commit: committing a large amount of capacity resources leads to large capacity market payments, but this comes at the cost of reducing the monopolist's energy market profits, given that in the event of recall, he will have to sell his energy at the national energy price cap, $P$, rather than at the foreign market price, $f$.

The monopolist solves this trade-off by choosing the capacity commitment, $\theta$, that maximizes his total profits $C \theta+\pi_{\mathrm{m}}(\theta)$, i.e. the sum of capacity payments plus energy market profits. The latter are given by,

$$
\begin{aligned}
\pi_{\mathrm{m}}(\theta)= & \int_{0}^{K-\beta}[P D+f \beta] \mathrm{d} G(D)+\int_{K-\beta}^{\bar{\theta}}[P D+f[K-D]] \mathrm{d} G(D)+\int_{\bar{\theta}}^{1}[P \bar{\theta} \\
& +f[K-\bar{\theta}]] \mathrm{d} G(D),
\end{aligned}
$$

where $\bar{\theta}=\max \{K-\beta, \theta\}$.

The first term in Eq. (1) represents the profit that the monopolist earns when demand does not exceed his non-exportable capacity: the monopolist satisfies all internal demand at a price $P$ and fully exploits his transmission line to export energy at a price $f$. The second element in Eq. (1) gives the profits made by the monopolist when demand is larger than his non-exportable capacity but still lower than his capacity commitment. In this case, the monopolist will sell his nonexportable capacity at $P$, and the difference between his commitment and his production will be recalled and paid at the prevailing energy price. Therefore, the monopolist will only be able to export what he can produce with its remaining productive capacity, so that the transmission capacity will no longer be binding. As represented by the third element of the equation, when demand exceeds the monopolist's capacity commitment, the monopolist will sell up to his commitment in the national energy market, and will export his remaining capacity. Last, note that if the monopolist cannot fulfill his commitment with his own productive capacity, i.e. $K<\theta$, he imports the difference from abroad (recall that he owns the transmission network). The monopolist thus makes profits $P \theta$ but loses the cost of the energy imported, that is $f$ times the excess of his commitment over his productive capacity, $[K-\theta]$. Overall, if $K<\theta$, the profit is the same as in the third term of Eq. (1).

Let us now assess the effect on the monopolist's profits of a marginal increase in his capacity commitment. First, for values $\theta \in[0, K-\beta]$, increases in $\theta$ have a positive marginal effect on the monopolist's profits, given that increases in $\theta$ within this interval have no effect on his energy market profits (the regulator cannot recall more than what the monopolist is already producing) but lead to larger capacity market revenues. This implies that the monopolist finds it always profitable to commit at least his non-exportable capacity resources.

For values $\theta \in[K-\beta, \Theta]$, a marginal increase in $\theta$ increases the monopolist's capacity revenues by $C$ but reduces his energy market profits by $[f-P][1-G(\theta)]$, where $[f-P]$ gives the price differential that the monopolist gives up when he marginally increases $\theta$, and $[1-G(\theta)]$ gives the probability of the marginal increment being recalled. Therefore, the monopolist's marginal opportunity cost from committing $\theta$ is given by $C-[f-P][1-G(\theta)]$. Clearly, the marginal benefit $C$ is independent of $\theta$, whereas the marginal cost $[f-P][1-G(\theta)]$ decreases with $\theta$. All this implies that the opportunity $\operatorname{cost}^{14}$ of listing capacity increases with $\theta$, or equivalently, that the monopolist's profit function $\pi_{\mathrm{m}}(\theta)+C \theta$ is convex in $\theta$ for $\theta \in[K-\beta, \Theta]$. Accordingly, we

\footnotetext{
14 Interestingly, the PJM Market Monitoring Unit (2001a) defines the opportunity costs of selling into the PJM market as "the additional revenue foregone from not selling into an external energy and/or capacity market".
} 
have corner solutions, with the monopolist either committing $K-\beta$ or $\Theta$ capacity resources, depending on the value of $C$.

The following proposition identifies the critical value of $C$ that determines the monopolist's optimal commitment:

Proposition 1. There exists $C_{m}=C_{m}(\Theta, K-\beta, f-P)$ such that the monopolist's optimal decision is to offer to commit at least $\Theta$ capacity resources if and only if $C \geq C_{m}$ (market clearing equilibrium) and to only offer to commit its non-exportable capacity, $K-\beta$, otherwise (capacitydeficit equilibrium).

The loss in the energy market revenues that the monopolist expects to give up from selling in the capacity market $\Theta$ instead of the non-exportable capacity $K-\beta$ is $\pi_{\mathrm{m}}(K-\beta)-\pi_{\mathrm{m}}(\Theta)$, while the gain is $C(\Theta-(K-\beta))$. Therefore, critical value $C_{\mathrm{m}}$ represents the price at which the capacity market revenues balance the energy market losses:

$$
C_{\mathrm{m}}=\frac{\pi_{\mathrm{m}}(K-\beta)-\pi_{\mathrm{m}}(\Theta)}{\Theta-(K-\beta)} .
$$

Using the profit expression (1) evaluated at $K-\beta$ and $\Theta$ gives

$$
C_{\mathrm{m}}=[f-P]\left[\int_{K-\beta}^{\Theta} \frac{D-(K-\beta)}{\Theta-(K-\beta)} d G(D)+[1-G(\Theta)]\right] \text {. }
$$

The level of demand in the capacity market $\Theta$ will affect the value of capacity market price ensuring full commitment through three effects. First, for a given demand realization below $\Theta$, increases in $\Theta$ raise capacity market gains and leave energy market losses unaffected; hence, within this range, the ratio of the losses over the gains goes down. Second, for a given demand realization above $\Theta$, increases in $\Theta$ raise capacity market gains and energy market losses in the same proportion, so that the ratio remains unaffected. And third, increases in $\Theta$ shift down (up) the probability of demand realizations above (below) $\Theta$. Since the ratio of the losses over the gains is higher when demand lies above $\Theta$ than when it lies below $\Theta$, the net benefit of committing $\Theta$ increases, for a given capacity choice.

Changes in the value non-exportable capacity $(K-\beta)$ only influence $C_{\mathrm{m}}$ for demand values below $\Theta$ (i.e. the first term in brackets in Eq. (3)). Over this range, increases in non-exportable capacity reduce more the energy market losses than the capacity market price decrease. Hence, $C_{\mathrm{m}}$ decreases with the value of non-exportable capacity.

Last, when a supplier chooses to commit capacity resources, it gives up the price differential between the foreign and national energy markets. Hence, the opportunity cost is increasing in $(f-P)$. In a more realistic context in which foreign prices fluctuate, our results predict that when there is no spread between the national and foreign energy prices, the opportunity costs of committing capacity falls to zero.

\section{Perfect competition}

Consider now the case of $n>1$ price-taking firms. Since both the energy and capacity markets are perfectly competitive, the energy equilibrium price will be equal to (zero) marginal costs, and the capacity equilibrium price will be given by the opportunity cost of committing capacity resources. 
Given that profits in the internal energy market will be zero, firms' revenues can only come from two sources: exports, which are paid at $f$, and capacity payments. The value of exports is constrained by the amount of committed resources that are recalled to satisfy internal demand. In the event of no recall, firms fully exploit the transmission line, thus making profits $\beta f$. If there is recall, which may occur whenever demand exceeds $K-\beta$, total exports are given by the value of total productive capacity net of those resources committed to satisfy the recall requirement.

Aggregate industry profits from selling energy are similar to those of the monopolist, except from the fact that the competitive firms make no profits in the internal energy market:

$$
\pi_{\mathrm{c}}(\theta)=\int_{0}^{K-\beta} \beta f \mathrm{~d} G(D)+\int_{K-\beta}^{\bar{\theta}}[K-D] f \mathrm{~d} G(D)+\int_{\bar{\theta}}^{1}[K-\bar{\theta}] f \mathrm{~d} G(D),
$$

where $\bar{\theta}=\max \{K-\beta, \theta\}$.

Notice that if the demand is larger than the non-exportable capacity, the price is equal to marginal cost given the availability of recalled resources. Indeed, demand always exceeds productive capacity (recall that by hypothesis $\mathrm{A} 2$ if the transmission line were fully utilized to import energy from the foreign market, this would be enough to satisfy peak electricity demand), therefore, in the energy market competitive firms do not earn scarcity rents.

The profit function in the capacity market is independent of $\theta$ for $\theta \in[0, K-\beta]$, while for higher values of the capacity commitment, $\theta \in[K-\beta, \Theta]$, firms earn (4) plus the capacity market revenues; over this latter range, capacity market profits are convex in $\theta$. Similarly to the monopoly case, if the price cap is larger than the opportunity cost of committing the total amount of resources demanded, the capacity market will clear at that cost. Otherwise, firms will optimally choose to only commit their non-exportable capacity.

The following proposition identifies the critical value of the opportunity $\operatorname{cost} C_{\mathrm{c}}$ that determines the competitive industry's optimal commitment:

Proposition 2. There exists $C_{c}=C_{c}(\Theta, K-\beta, f)$ such that the competitive industry's optimal decision is to offer to commit at least $\Theta$ capacity resources if $C \geq C_{c}$ (market-clearing equilibrium) and to only offer to commit the non-exportable capacity, $K-\beta$, otherwise (capacitydeficit equilibrium).

Again, the critical value $C_{\mathrm{c}}$ represents the price at which the capacity market revenues balance the energy market losses. Using the profit expression (4) evaluated at $K-\beta$ and $\Theta$ gives

$$
C_{\mathrm{c}}=f\left[\int_{K-\beta}^{\Theta} \frac{D^{-}(K-\beta)}{\Theta-(K-\beta)} \mathrm{d} G(D)+[1+G(\Theta)]\right] \text {. }
$$

A similar interpretation as the one given in the monopoly case can be applied here to show that increases in $\Theta$ and $(K-\beta)$ both have a negative impact on $C_{\mathrm{c}}$, and that if the neighboring energy market is as profitable as the internal one (i.e. $f=0$ ), or trade is impossible, supplying capacity comes at no cost.

It is straightforward to see that:

$$
C_{\mathrm{c}}=\frac{f}{f-P} C_{\mathrm{m}}>C_{\mathrm{m}}
$$

As long as the energy market abroad is as least as profitable as the national one (i.e. under the assumption $(f-P) \geq 0$ ), the costs of inducing market clearing in the capacity market are 
larger in the competitive case than in the monopoly case. The availability of resources through the capacity market keeps the prices at marginal cost in the energy market, and the capacity price provides the scarcity rents required to make it profitable for competitive generators to assure security of supply. Said differently, capacity obligations transfer funds to generators via capacity markets, and so, when these markets exist, they reduce the size and profitability of price spikes (Stoft, 2002). Clearly, giving up the external price $f$ to earn a price equal to marginal costs if recalled is more costly than giving it up in exchange of earning $P$ in the event of recall. Therefore, it is more expensive to have capacity available in a competitive market than in a monopolistic one. This result will qualitatively hold when there are different production technologies in the national energy market, ranked by merit order, as long as the monopolist always bids at $P$ and competitive firms at marginal cost (and the price cap is not binding).

\section{The regulator's problem}

In this section we solve the regulator's problem, under the assumption that he has complete information concerning the value of firms' opportunity costs. The regulator's decision is two-fold. First, he has to decide whether to introduce a capacity market or not. And second, in the case in which the regulator has introduced a capacity market, he has to choose how many resources to demand in the capacity market, $\Theta$, and has to set the capacity price cap, $C$. It is assumed that the regulator aims at maximizing total surplus, defined as the sum of consumer surplus plus a share of suppliers' profits, weighted by the parameter $\alpha \in[0,1]$.

The following propositions identify the conditions under which introducing a capacity market is preferred over power curtailments as a source of reserves. They also characterize the optimal capacity obligation and price caps, both under monopoly as under perfect competition.

Proposition 3. Under monopoly,

(i) There exists $\underline{v}_{m}=\underline{v}_{m}(\alpha, f, P, K-\beta)$ such that the regulator finds it optimal to introduce a capacity market if and only if $v>\underline{v}_{m}$.

(ii) If $v>\underline{v}_{m}$, the regulator's optimal choice of the capacity obligation equals peak demand, $\Theta_{m}^{*}=1$, and his optimal choice of the capacity price cap equals the minimum value at the which the capacity market clears, $C_{m}^{*}=C_{m}(1, K-\beta, f-P)$.

The previous proposition shows that $v$ needs to be large enough in order to make it optimal to introduce a capacity market. Otherwise, the costs of inducing the monopolist to commit as many resources so as to cover the reserve margin would be too large with respect to the gains of avoiding shortages.

As the parameter $v$ can be interpreted as the price consumers would be willing to pay in case of power curtailment, and given that "a unit of electricity not requested by a customer has the same effect as an additional unit of electricity being generated" (FERC, 2001), only for large values of $v$ it is optimal to create a capacity market rather than to resort to voluntary curtailment as a source of reserves.

Interestingly enough, the larger the price cap, the lower will be the critical value of $v$ above which having a capacity market is optimal. The reason is that a higher $P$ leads to lower opportunity costs of committing capacity resources, and hence to lower capacity payments. In other words, having a capacity market in a 'price-spike world' is cheap, and it may even turn out to be unnecessary when the price cap $P$ is so large that it exceeds the foreign price $f$ (see Corollary 
2 below). Similarly, the smaller the transmission capacity and the lower the prevailing foreign energy price, the lower are the monopolist's opportunity costs, and hence, the lower is the critical $v$ needed to make the capacity market optimal.

If the regulator has decided to introduce a capacity market, his optimal choice would be to set the capacity obligation at a level that guarantees no shortages, i.e. to set it equal to peak demand. ${ }^{15}$ This does not only avoid the losses from power curtailment, but it also reduces total capacity payments paid to the monopolist.

Similar results can be derived for the competitive scenario.

Proposition 4. Under perfect competition,

(i) There exists $\underline{v}_{c}=\underline{v}_{c}(\alpha, f, K-\beta)$ such that the regulator finds it optimal to introduce a capacity market if and only if $v>\underline{v}_{c}$.

(ii) For all $v>\underline{v}_{c}$, the regulator's optimal choice of the capacity obligation equals peak demand, $\Theta_{c}^{*}=1$, and his optimal choice of capacity price cap equals the minimum value at the which the capacity market clears, $C_{c}^{*}=C_{c}(1, K-\beta, f)$.

The comparison of $\underline{v}_{\mathrm{m}}$ and $\underline{v}_{\mathrm{c}}$ shows ${ }^{16}$ that having a capacity market may be optimal under monopoly and suboptimal under perfect competition, i.e. $\underline{v}_{\mathrm{c}} \geq \underline{v}_{\mathrm{m}}$. This is so since the capacity payments needed to induce market clearing under perfect competition exceed those under monopoly, since by Eq. (6), $C_{\mathrm{c}}^{*}>C_{\mathrm{m}}^{*}$. If firms' profits are fully taken into account by the regulator $(\alpha=1)$, the difference between the two threshold values $\underline{v}_{\mathrm{m}}$ and $\underline{v}_{\mathrm{c}}$ vanishes.

Nevertheless, as shown in the following corollary, even if capacity payments are larger under perfect competition, the difference does not compensate for the higher energy prices that have to be paid under monopoly. This implies that it is preferable to have a stringent pricing policy and an active competition policy in the energy market (i.e. low $P$ and a larger number of firms) even it implies increasing capacity payments up to the point at which having a capacity market may no longer be optimal.

Corollary 1. If $\alpha<1$, the total level of welfare is always larger under perfect competition as compared to monopoly, regardless of whether having a capacity market is optimal or not, and regardless of the level of the optimal capacity payments.

To conclude this section, we have analyzed the optimality of resorting to an alternative source of reserves in the monopoly case (this alternative is inconsequential under perfect competition, given that the price cap is never binding). If the regulator 'imports the foreign price spike' by setting $P=f$, he guarantees that the monopolist does not export his energy, since he is indifferent between selling it in the foreign or in the national market (the critical price at which the capacity market revenues balance the energy market losses falls to zero-see Eq. (3)). Therefore, the need of a capacity market would be eliminated.

Corollary 2. In the monopoly case, independently of $v$, it is not optimal to import the foreign price spike, i.e. to set $P=f$, in order to avoid the need of a capacity market.

\footnotetext{
15 Recall that, for simplicity, we are assuming away the probability of capacity or transmission outages. Introducing them would not change our analysis in any significant way. For instance, if we allowed for random capacities, $K$ and $\beta$ would just stand for the expected values of production and transmission capacities. The optimal reserve margin would then come close to what is required by the standard reliability rules (Billinton and Allan, 1996).

${ }^{16}$ It can be easily shown that $\underline{v}_{\mathrm{c}}-\underline{v}_{\mathrm{m}}=P(1-\alpha)(K-\beta) /[1-(K-\beta)] \geq 0$.
} 
The reason for the above result is that the foreign market price affects the capacity payment only partially, whereas importing it by setting $P=f$ implies that a higher energy price will be paid by consumers at all times. Thus, creating reserves through a capacity market is preferable to avoid exports through increased market prices.

\section{Conclusions}

We have developed a simple model aimed at capturing some of the main features of electricity capacity markets, both under perfect competition and monopoly. Since we take production and transmission capacities as given, we cannot analyze whether capacity markets give incentives for capacity expansions that would ultimately contribute to relax market power problems in the energy market. Instead, we have characterized firms' optimal behavior and equilibrium outcomes, and addressed some of the regulatory issues involved in the design of these markets to ensure supply security.

First, we have identified the factors that determine the opportunity costs of committing capacity resources. When a generator commits a fraction of its capacity resources, he faces a trade-off: committing more capacity resources implies larger revenues through the capacity market, but it also implies that, in the event of recall, such a generator will have to give up the revenue from alternative sales, i.e. the price differential between the foreign and national energy prices. Therefore, under both competition and monopoly, the more profitable the foreign energy market relative to the national one, the higher the opportunity costs of committing capacity resources, and the larger the capacity payments required to induce full commitment. This observation is consistent with the evidence that, during the summer of 2000, the PJM capacity markets experienced price spikes at the same time as energy prices were fairly low, notwithstanding competitive behavior of market participants (see PJM, 2001a,b).

Furthermore, our model shows that the opportunity costs of committing capacity are also a function of the probability of recall, the amount of the resources required to ensure supply security and the transmission capacity. Most importantly, the intensity of price competition in the energy market matters: decreasing spot market prices through more intense competition (or lower price caps) may come at the cost of increasing capacity payments. Our model also suggests that capacity markets may clear at zero prices (as in PJM during April 2001, see PJM, 2001b) if there is no spread between national and foreign energy prices, if non-exportable resources are enough to satisfy all capacity obligations, or if the system has excess capacity so that the probability of recall falls to zero.

We have also analyzed firms' optimal behavior in the capacity market, and thus equilibrium outcomes. Depending on the value of the capacity price cap and the value of the capacity obligation set by the regulator, two types of equilibria may arise. First, the capacity-deficit equilibrium, in which generators only commit the fraction of their capacities that has no opportunity costs but the required resources exceed the supply. And second, the market-clearing equilibrium, in which generators jointly offer to commit enough capacity resources so as to cover the capacity obligation (and in fact eliminate the probability of shortages). Whether the first or the second type of equilibria arise mainly depends on the capacity price cap: if it is too low, generators' opportunity costs would not be covered, and a capacity deficit would arise. Thus, even in the presence of capacity markets, the system could be short of resources, endangering the security of supply. For instance, this has been the case in PJM during the summer of 2000 or in January 2003 (see PJM, 2001b, 2004). 
We have assessed the desirability of introducing capacity markets, and characterized the optimal capacity obligation and price cap in these markets. Capacity markets, if well designed, contribute to improved supply security, because they allow capacity resources to be recalled when needed. For this mechanism to maximize social welfare, the gains from avoiding power curtailments must exceed its costs. When this condition holds, it is optimal to set capacity obligations equal to peak demand (plus expected outages) and to fix the capacity price cap at a level equal to firms' opportunity costs of providing full capacity commitment. Any departure from this level either undermines the functioning of these markets, by overpaying capacity, or leaves scope for the exercise of market power, as in the PJM capacity market during the first quarter of 2001.

\section{Acknowledgements}

This paper has benefited from comments by Alain Bousquet, Claude Crampes, Alfredo Garcia, Paul Joskow, Karsten Neuhoff, Jean Tirole, two anonymous referees, and seminar participants at the IDEI-CEPR Conference on Competition and Coordination in the Electricity Industry, held in Toulouse, January 2004. All errors remain our own responsibility. The second author would like to thank the University of California Energy Institute, the IDEI and Fundación Ramón Areces for support during the preparation of the paper.

\section{Appendix A. Proofs}

\section{A.1. Monopoly}

Proof of Proposition 1. For a given capacity commitment $\theta$, the monopolist's total profits are equal to $C \theta+\pi_{\mathrm{m}}(\theta)$, where $\pi_{\mathrm{m}}(\theta)$ is given in (1). Taking the first and second derivatives of the monopolist's total profit with respect to $\theta$,

$$
\begin{aligned}
& \frac{\partial\left[\pi_{\mathrm{m}}(\theta)+C \theta\right]}{\partial \theta}= \begin{cases}C & \text { if } \theta \leq K-\beta \\
C-[f-P][1-G(\theta)] & \text { if } \theta>K-\beta\end{cases} \\
& \frac{\partial^{2}\left[\pi_{\mathrm{m}}(\theta)+C \theta\right]}{\partial \theta^{2}}=\left\{\begin{array}{ll}
0 & \text { if } \theta \leq K-\beta \\
{[f-P] g(\theta)} & \text { if } \theta>K-\beta
\end{array} .\right.
\end{aligned}
$$

Given that $\frac{\partial\left[\pi_{\mathrm{m}}(\theta)+C \theta\right]}{\partial \theta}>0$ for $\theta \leq K-\beta$, then offering to commit any amount lower than $K-\beta$ is dominated by offering to commit $K-\beta$. Given $\frac{\partial^{2}\left[\pi_{\mathrm{m}}(\theta)+C \theta\right]}{\partial \theta^{2}}>0$ for $\theta>K-\beta$ the monopolist will optimally offer to commit either $K-\beta$ or at least $\Theta$ capacity resources.

He will choose to commit $\Theta$ if and only if:

$$
C \Theta+\pi_{\mathrm{m}}(\Theta) \geq C[K-\beta]+\pi_{\mathrm{m}}(K-\beta) .
$$

Rearranging terms,

$$
C \geq C_{\mathrm{m}}=\frac{\pi(K-\beta)-\pi(\Theta)}{\Theta-[K-\beta]},
$$


and using (1), simple algebra leads to,

$$
C_{\mathrm{m}}=[f-P]\left[\int_{K-\beta}^{\Theta}\left[\frac{D-[K-\beta]}{\Theta-[K-\beta]}\right] \mathrm{d} G(D)+[1-G(\Theta)]\right] .
$$

Last, some comparative statics:

$$
\begin{aligned}
& \frac{\partial C_{\mathrm{m}}}{\partial \Theta}=-\frac{f-P}{[\Theta-[K-\beta]]^{2}} \int_{K-\beta}^{\Theta}[D-[K-\beta]] \mathrm{d} G(D)<0 . \\
& \frac{\partial C_{\mathrm{m}}}{\partial(K-\beta)}=-\frac{f-P}{[\Theta-[K-\beta]]^{2}} \int_{K-\beta}^{\Theta}[\Theta-D] \mathrm{d} G(D)<0 . \\
& \frac{\partial C_{\mathrm{m}}}{\partial(f-P)}=\int_{K-\beta}^{\Theta}\left[\frac{D-[K-\beta]}{\Theta-[K-\beta]}\right] \mathrm{d} G(D)+[1-G(\Theta)]>0 .
\end{aligned}
$$

\section{A.2. Perfect competition}

Proof of Proposition 2. The first part of the proof is similar to that of the monopolist (the single difference is that all the terms multiplied by $P$ in the monopolist's profit expressions disappear under perfect competition). Hence, we move directly to the characterization of the opportunity costs of committing $\Theta$ rather than $K-\beta$. The competitive industry will choose to commit $\Theta$ if and only if:

$$
c \Theta+\pi_{\mathrm{c}}(\Theta) \geq c[K-\beta]+\pi_{\mathrm{c}}(K-\beta) .
$$

where $c$ is the equilibrium price in the capacity market. Rearranging terms,

$$
c \geq C_{\mathrm{c}}=\frac{\pi_{\mathrm{c}}(K-\beta)-\pi_{\mathrm{c}}(\Theta)}{\Theta-[K-\beta]} .
$$

Given perfect competition, the equilibrium price will equal $C_{\mathrm{c}}$ as long as this price is below the price cap $C$. Using the profit expression (4) and solving for $C_{\mathrm{c}}$,

$$
C_{\mathrm{c}}=f\left[\int_{K-\beta}^{\Theta}\left[\frac{D-[K-\beta]}{\Theta-[K-\beta]}\right] \mathrm{d} G(D)+[1-G(\Theta)]\right] .
$$

Last, given that $C_{\mathrm{c}}=\frac{f}{f-P} C_{\mathrm{m}}$ the comparative statics of $C_{\mathrm{c}}$ with respect to $\Theta$ and $K-\beta$, and $f$ are the same as in the monopoly case.

\section{A.3. The regulator's problem}

Proofs of Propositions 3 and 4. The regulator has to decide whether to create or not a capacity market; in the case in which he has decided to create a capacity market, he has to set a capacity obligation and a capacity market price cap. We will analyze these two decisions by backward induction first for the monopoly case, and second for the case of perfect competition. Throughout, its is assumed that the regulator aims at maximizing the sum of consumer surplus (every unit consumed reports a utility equal to $v>f>P$ ) plus an $\alpha \in[0,1]$ share of producers' surplus. 
Monopoly:

Assume that the regulator has created a capacity market. Clearly, we can ignore two cases: first, $\Theta \leq K-\beta$ - paying for capacity resources that the monopolist would in any case offer in the energy market would increase costs without decreasing shortages; and second $C<C_{\mathrm{m}}$-by Proposition 1, the monopolist would just offer its non-exportable capacity that he would use to produce internally even without a capacity market. Hence, we focus on parameter values $\Theta \in(K-\beta, 1]$ and $C \geq C_{\mathrm{m}}$. Total welfare is given by:

$$
\begin{aligned}
W_{\mathrm{m}}^{C}(\Theta, C)= & {[v-P]\left[\int_{0}^{\Theta} D \mathrm{~d} G(D)+\Theta[1-G(\Theta)]\right]-C \Theta } \\
& +\alpha\left[\int_{0}^{K-\beta}[D P+\beta f] \mathrm{d} G(D)+\int_{K-\beta}^{\Theta}[D P+[K-D] f] \mathrm{d} G(D)\right] \\
& +\alpha\left[\int_{\Theta}^{1}[P \Theta+[K-\Theta] f] \mathrm{d} G(D)+C \Theta\right]
\end{aligned}
$$

Total welfare ${ }^{17}$ can be rewritten as

$$
\begin{aligned}
W_{\mathrm{m}}^{C}(\Theta, C)= & {[v-[1-\alpha] P]\left[\int_{0}^{\Theta} D \mathrm{~d} G(D)+\Theta[1-G(\Theta)]\right] } \\
& +\alpha f\left[\beta G(K-\beta)+\int_{K-\beta}^{\Theta}[K-D] \mathrm{d} G(D)+[K-\Theta][1-G(\Theta)]\right]-[1-\alpha] C \Theta .
\end{aligned}
$$

Clearly, $W_{\mathrm{m}}^{C}(\Theta, C)$ is decreasing in $C$. Hence, the regulator will set $C$ equal to the minimum level that induces the monopolist to commit the desired $\Theta$, i.e. $C=C_{\mathrm{m}}$.

The first derivative of $W_{\mathrm{m}}^{C}\left(\Theta, C_{\mathrm{m}}\right)$ with respect to $\Theta$ is given by:

$$
\frac{\partial W_{\mathrm{m}}^{C}\left(\Theta, C_{\mathrm{m}}\right)}{\partial \Theta}=[v-f][1-G(\Theta)]+[1-\alpha][f-P] \frac{[K-\beta]}{\Theta-[K-\beta]} \int_{K-\beta}^{\Theta}\left[\frac{D-[K-\beta]}{\Theta-[K-\beta]}\right] \mathrm{d} G(D)>0 .
$$

It is therefore optimal to set the capacity obligation equal to peak demand, $\Theta_{\mathrm{m}}^{*}=1$. The resulting level of welfare is given by

$$
\begin{aligned}
W_{\mathrm{m}}^{C}\left(1, C_{\mathrm{m}}\right)= & {[v-[1-\alpha] P]\left[\int_{0}^{1} D \mathrm{~d} G(D)\right]+\alpha f\left[\beta G(K-\beta)+\int_{K-\beta}^{1}[K-D] \mathrm{d} G(D)\right] } \\
& -[1-\alpha][f-P] \int_{K-\beta}^{1} \frac{D-[K-\beta]}{1-[K-\beta]} \mathrm{d} G(D) .
\end{aligned}
$$

Let us now analyze the regulator's decision of whether or not to introduce a capacity market. In the absence of a capacity market, only the non-exportable capacity $K-\beta$ is offered. Total welfare is given by:

$$
\begin{aligned}
W_{\mathrm{m}}^{\mathrm{NC}}= & {[v-P]\left[\int_{0}^{K-\beta} D \mathrm{~d} G(D)+[K-\beta][1-G(K-\beta)]\right] } \\
& +\alpha\left[\int_{0}^{K-\beta}[D P+\beta f] \mathrm{d} G(D)+[P[K-\beta]+\beta f][1-G(K-\beta)]\right] .
\end{aligned}
$$

\footnotetext{
${ }^{17}$ Notice that for demand above $\Theta$, the regulator cannot import energy as the monopolist owns non-tradable transmission rights.
} 
which can also be rewritten as

$$
W_{\mathrm{m}}^{\mathrm{NC}}=\left[v^{-}[1-\alpha] P\right]\left[\int_{0}^{K-\beta} D \mathrm{~d} G(D)+[K-\beta][1-G(K-\beta)]\right]+\alpha \beta f .
$$

Thus, for the regulator to optimally choose to implement a capacity market, we require that (7) exceeds (8). Taking the difference between the two gives

$$
W_{\mathrm{m}}^{C}\left(1, C_{\mathrm{m}}\right)-W_{\mathrm{m}}^{\mathrm{NC}}=\left[[v-P]-[f-P] \frac{1-\alpha[K-\beta]}{1-[K-\beta]}\right] \int_{K-\beta}^{1}[D-[K-\beta]] \mathrm{d} G(D)
$$

which depends on the sign of the first element on the RHS. Straightforward calculations show that this element is positive if and only if

$$
v>\underline{v}_{\mathrm{m}}(\alpha, f, P, K-\beta)=[f-P] \frac{1-\alpha[K-\beta]}{1-[K-\beta]}+P .
$$

The sign of the derivatives of $\underline{v}_{\mathrm{m}}$ with respect to $\alpha$ and $f$ is straightforward. Moreover:

$$
\begin{gathered}
\frac{\partial \underline{\underline{v}}_{m}}{\partial P}=-\frac{[1-\alpha][K-\beta]}{1-[K-\beta]}<0 . \\
\frac{\partial \underline{v}_{m}}{\partial[K-\beta]}=\frac{[f-P][1-\alpha]}{[1-(K-\beta)]^{2}}>0 .
\end{gathered}
$$

Perfect competition:

We use a similar reasoning as above; recall that the price in the energy market is now equal to (zero) marginal production costs.

Assume that the regulator has created a capacity market and focus on parameter values $\Theta \in(K-\beta, 1]$ and $C \geq C_{\mathrm{c}}$. Total welfare is given by:

$$
\begin{aligned}
W_{\mathrm{c}}^{C}(\Theta, C)= & v\left[\int_{0}^{\Theta} D \mathrm{~d} G(D)+\Theta[1-G(\Theta)]\right] \\
& +\alpha f\left[\beta G(K-\beta)+\int_{K-\beta}^{\Theta}[K-D] \mathrm{d} G(D)+[K-\Theta][1-G(\Theta)]\right]-[1-\alpha] C \Theta .
\end{aligned}
$$

Clearly, $W_{\mathrm{c}}^{C}(\Theta, C)$ is decreasing in $C$. Hence, the regulator will set $C$ equal to the minimum level that induces the monopolist to commit the desired $\Theta$, i.e. $C=C_{\mathrm{c}}$.

The first derivative of $W_{\mathrm{c}}^{C}\left(\Theta, C_{\mathrm{c}}\right)$ with respect to $\Theta$ is given by:

$$
\frac{\partial W_{\mathrm{c}}^{C}\left(\Theta, C_{\mathrm{c}}\right)}{\partial \Theta}=[v-f][1-G(\Theta)]>0 .
$$

It is therefore optimal to set the capacity obligation equal to peak demand, $\Theta_{c}^{*}=1$. The resulting level of welfare is given by:

$$
\begin{aligned}
W_{\mathrm{c}}^{C}\left(1, C_{\mathrm{c}}\right)= & v \int_{0}^{1} D \mathrm{~d} G(D)+\alpha f\left[\beta G(K-\beta)+\int_{K-\beta}^{1}[K-D] \mathrm{d} G(D)\right]-[1-\alpha] f \int_{K-\beta}^{1} \frac{D-[K-\beta]}{1-[K-\beta]} \\
& \times \mathrm{d} G(D) .
\end{aligned}
$$


Total welfare in the absence of a capacity market is given by:

$$
W_{\mathrm{c}}^{\mathrm{NC}}=v\left[\int_{0}^{K-\beta} D \mathrm{~d} G(D)+[K-\beta][1-G(K-\beta)]\right]+\alpha \beta f
$$

Thus, for the regulator to optimally choose to introduce a capacity market, we require that (9) exceeds (10). Taking the difference between the two gives

$$
W_{\mathrm{c}}^{C}\left(1, C_{\mathrm{c}}\right)-W_{\mathrm{c}}^{\mathrm{NC}}=\left[v-f \frac{1-\alpha[K-\beta]}{1-[K-\beta]}\right]\left[\int_{K-\beta}^{1}[D-[K-\beta]] \mathrm{d} G(D)\right] .
$$

which depends on the sign of the first element on the RHS. Straightforward calculations show that this element is positive if and only if

$$
v>\underline{v}_{\mathrm{c}}(\alpha, f, K-\beta)=f \frac{1-\alpha[K-\beta]}{1-[K-\beta]} .
$$

The sign of the derivatives of $\underline{v}_{\mathrm{c}}$ with respect to $\alpha, f$ and $(K-\beta)$ is straightforward and does not contradict comparative statics results found for the monopoly case.

Proof of Corollary 1. When having a capacity market is optimal in both the monopoly and the perfect competition cases, i.e. $v \geq \underline{v}_{\mathrm{c}}$ :

$$
W_{\mathrm{m}}^{C}-W_{\mathrm{c}}^{C}=-[1-\alpha] P\left[\int_{0}^{K-\beta} D \mathrm{~d} G(D)+\frac{[K-\beta]}{1-[K-\beta]} \int_{K-\beta}^{1}[1-D] \mathrm{d} G(D)\right]<0 .
$$

which is clearly negative.

When having a capacity market is optimal under monopoly but not under perfect competition, i.e. $\underline{v}_{\mathrm{m}} \leq v<\underline{v}_{\mathrm{c}}$, we have $W_{\mathrm{m}}^{C}-W_{\mathrm{c}}^{\mathrm{NC}} \leq W_{\mathrm{m}}^{C}-W_{\mathrm{c}}^{C}<0$ given that $W_{\mathrm{c}}^{\mathrm{NC}}>W_{\mathrm{c}}^{C}$.

When having a capacity market is not optimal neither under monopoly nor under perfect competition, i.e. $v<\underline{v}_{\mathrm{m}}$, we have $W_{\mathrm{c}}^{\mathrm{NC}}>W_{\mathrm{m}}^{\mathrm{NC}}$ since consumer surplus is trivially larger under perfect competition.

Proof of Corollary 2. If the regulator sets $P=f$, the resulting level of welfare surplus is equal to

$$
\left.W_{\mathrm{c}}^{\mathrm{NC}}\right|_{P=f}=[v-f] \int_{0}^{1} D \mathrm{~d} G(D)+\alpha K f
$$

Assume $v>v_{\mathrm{m}}$. For the regulator to optimally choose to implement a capacity market rather than to import the foreign price spike, we require that (7) exceeds (11). Taking the difference,

$$
\begin{aligned}
\left.W_{\mathrm{m}}^{C}\right|_{P<f}-\left.W_{\mathrm{m}}^{\mathrm{NC}}\right|_{P=f}= & {[1-\alpha][f-P]\left[\int_{0}^{K-\beta} D \mathrm{~d} G(D)+\int_{K-\beta}^{1}(1-D) \frac{K-\beta}{1-[K-\beta]} \mathrm{d} G(D)\right] } \\
& +\alpha f \int_{0}^{K-\beta}[D-[K-\beta]] \mathrm{d} G(D) .
\end{aligned}
$$

which is always positive and independent of $v$. That is, it is preferable to have a capacity market, rather than to import the price spike, no matter how small $f$ is. 
Assume $v \leq v_{\mathrm{m}}$. Thus, for the regulator to optimally choose not to implement a capacity market and set $P<f$ rather than to import the foreign price spike, we require that (8) exceeds (11). Since $\left.W_{\mathrm{m}}^{C}\left(1, C_{\mathrm{m}}(1)\right)\right|_{P<f}>\left.W_{\mathrm{m}}^{\mathrm{NC}}\right|_{P=f}$ for every value of $v$, and $W_{\mathrm{m}}^{C}\left(1, C_{\mathrm{m}}(1)\right)<\left.W_{\mathrm{m}}^{\mathrm{NC}}\right|_{P<f}$ for $v \leq \underline{v}_{\mathrm{m}}$, it follows that

$$
\left.W_{\mathrm{m}}^{\mathrm{NC}}\right|_{P<f}>\left.W_{\mathrm{m}}^{\mathrm{NC}}\right|_{P=f}
$$

That is, it is preferable not to have a capacity market, rather than importing the price spike, no matter how small $f$ is.

\section{References}

Billinton, R., Allan, R.N., 1996. Reliability Evaluation of Power Systems, 2nd ed. Plenum Press, New York.

Borenstein, S., Holland, S., 2003. On the Efficiency of Competitive Electricity Markets With Time-Invariant Retail Prices. CSEM WP-116. Available at http://www.ucei.berkeley.edu/pubs-csemwp.html.

Bowring, J.E., Gramlich, R.E., 2000. The role of capacity obligations in a restructured Pennsylvania-New JerseyMaryland electricity market. The Electricity Journal 57-67.

CA-ISO, 2002a. Background Paper, Comparison of Capacity Obligations and Markets. Prepared by Power Economics, available at http://www.caiso.com.

CA-ISO, 2002b. CA-ISO Market Design Proposal. Available at http://www.caiso.com.

Cramton, P.C., Stoft, S., 2005. A capacity market that makes sense. Electricity Journal 18, 43-54 (August/September).

FERC (2001), Docket No. EL01-63-003, available at http://www.pjm.com.

Forsberg, K., Fritz, P., 2001. Methods to Secure Peak Load Capacity on Deregu-lated Electricity Markets” Paper Presented at the Market Design 2001 Conference in Saltsjöbaden, Sweden 7-8 June.

Hobbs, B.F., Inon, J., Kahal, M., 2001. Issues concerning ICAP and alternative approaches for power capacity markets. Papers and Proceeding, Market Design 2001 Conference, Elsfork, Sweden.

Joskow, P.L., 2003. The Blackout. MIT, mimeo, available at http://econ-www.mit.edu/faculty/?prof_id=pjoskow.

Joskow, P.L., 2005. Supply Security in Competitive Electricity and Natural Gas Market, Beesley Lecture, London, available at http://econ-www.mit.edu/faculty/?prof_id=pjoskow.

Joskow, P.L., Tirole, J., in press. Retail electricity competition. Rand Journal of Economics.

Klein, A.W., 2001. Do We Need ICAP? Ensuring Adequate Capacity in a Competitive Electricity Market. Presentation to Harvard Electricity Policy Group.

Newbery, D., 1995. Power markets and market power. Energy Journal 16 (3), 41-66.

Oren, S.S. 2003. Ensuring Generation Adequacy in Competitive Electricity Markets. Mimeo, University of California at Berkeley.

PJM, Monitoring Market Unit, 2000. State of the Market Annual Report, available at http://www.pjm.com.

PJM, Monitoring Market Unit, 2001a. State of the Market Annual Report, available at http://www.pjm.com.

PJM, Monitoring Market Unit, 2001b. Report to the Pennsylvania Public Utility Commission — Capacity Market Questions, available at http://www.pjm.com.

PJM, Monitoring Market Unit, 2003. State of the Market Annual Report, available at http://www.pjm.com.

PJM, Monitoring Market Unit, 2004. State of the Market Annual Report, available at http://www.pjm.com.

Stoft, S., 2002 Power System Economics. Designing Markets for Electricity. Wiley IEEE Press.

The Economist, 2003. The Day the Lights Went Off. The Economist Global Agenda, August 15.

Vázquez, C., Batlle, C., Rivier, M., Pérez Arriaga, J.I., 2003. Security of Supply in the Dutch Electricity Market: the Role of Reliability Options. Report prepared for the Office for Energy Regulation of The Netherlands. Available at http:// www.ksg.harvard.edu/hepg/Papers.

von der Fehr, N.-H., Amundsen, M., Bergman, E.S., 2005. The Nordic market: signs of stress? The Energy Journal 26 (Special Edition on European Electricity Liberalization, July).

Wolak, F.A., Patrick, R.H., 1997. The Impact of Market Rules and Market Structure on the Price Determination Process in the England and Wales Electricity Market. Power Working Paper 047. University of California at Berkeley. 